\title{
Tecnologias digitais e jovens usuários de serviço de saúde mental
}

\section{Digital Technologies and young users of a mental health service}

Resumo: Este artigo aborda uma experiência de utilização de tecnologias digitais na área da saúde mental, tendo como foco analisar a construção compartilhada de um blog por jovens usuários de um serviço de saúde mental. A conversa instituída a partir das postagens, do endereçamento a um coletivo e do acesso uma gama de imagens são indicadores de facilitação a uma posição de autoria.

Palavras-chave: Oficinas. Blog. Saúde mental. Autoria.

Abstract: This article discusses an experience of using digital technologies in the field of mental health. The focus of this work is to analyze the shared construction of a blog by young users of a mental health service. The conversation deriving from the postings, from the act of addressing a collective and from the access to a choice of images are indicators of facilitation of an authorship position.

Keywords: Workshops. Blog. Mental health. Authorship.
CAPELLA, Nithiane; MARASCHIN, Cleci; MAURENTE, Vanessa; RICKES, Simone Moschen. Tecnologias digitais e jovens usuários de serviço de saúde mental. Informática na educação: teoria \& prática. Porto Alegre, v.11, n.1, p. 79-90, jan./jun. 2008.
Nithiane Capella

Cleci Maraschin

Vanessa Maurente

Simone Moschen Rickes

Universidade Federal do Rio Grande do Sul, Porto Alegre, Brasil

\section{Introdução}

A pesar dos chamados ambientes de aprendizagem, possibilitados pela implementação de tecnologias digitais, terem-se tornado um objeto de significativa apropriação e análise na educação, não se observa o mesmo processo na área da saúde. No campo da saúde mental, do qual trata este artigo, embora existam importantes iniciativas - tal como o da TV Pinel, projeto do hospital psiquiátrico Philippe Pinel, no Rio de Janeiro (LEITE; FILÉ, 2002); oficinas tecnológicas e de produção de vídeos em CAPs, no Rio Grande do Sul (FRANCISCO, 2004; RAINONE, 2007) e capacitação dos trabalhadores dos serviços de saúde utilizando-se da educação à distância (PAULON, 2007) - há necessidade de maiores investimentos e estudos para subsidiar políticas públicas de saúde que possam utilizar como ferramentas de intervenção e de capacitação as tecnologias digitais.

Os resultados de nossos estudos no campo da educação (DEMOLY; MARASCHIN, 2007A, 2007B; RODRIGUES; MARASCHIN; LAURINO, 2007; REAL; MARASCHIN; AXT, 2007) entusiasmaram-nos a ampliar a pesquisa abran- 
gendo o campo da saúde. Nos estudos citados no domínio educativo podemos observar que as tecnologias digitais favorecem uma nova sinergia coletiva, oportunizando tanto aos estudantes quanto aos seus professores a constituição de redes de conversação e de produção que não são suficientemente exploradas nas práticas escolares cotidianas. Tais resultados, aliados ao estudo das potencialidades do uso de oficinas tecnológicas junto a adultos em um serviço de saúde mental no interior do estado do Rio Grande do Sul (FRANCISCO; AXT; MARASCHIN, 2007), foram fundamentais para a proposição tanto metodológica, quanto ética da intervenção que tomamos como objeto de reflexão neste artigo. A perspectiva desse texto é, por tanto, analisar uma experiência de utilização dessas tecnologias no campo da saúde, mais especificamente, da saúde mental.

Desde o ano de 2005 estamos desenvolvendo o Projeto "Oficinando em Rede", através de um convênio entre o Instituto de Psicologia, a Faculdade de Educação da UFRGS e o Hospital Psiquiátrico São Pedro (HPSP) em Porto Alegre. Por meio desse projeto, um laboratório de informática foi instalado na unidade infantil e adolescente do Hospital, o Centro Integrado de Atenção Psicossocial (CIAPS), onde são realizadas oficinas tecnológicas (escrita, informática, fotografia e robótica) com crianças e adolescentes usuários do serviço e com os trabalhadores do local. Todo o trabalho é desenvolvido em Software Livre, uma vez que, a possibilidade de reconfiguração dos recursos técnicos, vai ao encontro do exercício da autoria e não somente da utilização das tecnologias como utilitários. Por constituir-se em uma proposta que congrega pesquisa e extensão, o laboratório se mantém ativo desde sua implementação, ganhando a freqüência gradual dos trabalhadores do hospital, além da equipe de pesquisa.

As oficinas ocorrem sob duas modalidades: como propostas pontuais, com grupo e tempo determinado ou como atividade semanal permanente que configura a grade de atividades do serviço. De modo geral, os encontros são formados de quatro a seis oficinantes com idades próximas, além de dois oficineiros (pesquisador e técnico do serviço). Durante aproximadamente uma hora e meia, o espaço proposto à oficina é resultado de diversos elementos, tais como, os temas geradores das produções, as tecnologias utilizadas, assim como os meios de se apropriar da proposta afeitos aos interesses e possibilidades do grupo. Cabe aos oficineiros, o trabalho de mediação entre eles, não caracterizando o espaço como um território exclusivo de aprendizagem no uso dessas tecnologias, mas também como lugar onde o acento recai sobre a interação e a comunicação entre participantes e destes com o fora da instituição. A ênfase na apropriação tecnológica é principalmente lúdica e exploratória.

O projeto "Oficinando em Rede" foi idealizado, tendo como principal objetivo estudar como as tecnologias podem favorecer a constituição de redes de convivência por crianças e adolescentes em situação de grave sofrimento psíquico. Nesses dois anos de existência do Oficinando em Rede, empenhamo-nos em desenvolver estudos para dar sustentação a esse objetivo. Os primeiros estudos sobre as redes de convivência dos jovens que internam no serviço (SCISLESKI, 2004; SCISLESKI; MARASCHIN; NEVES, 2008) apontaram para a precariedade das redes sociais e institucionais pelas quais esses jovens circulam. Os resultados reforçaram a relevância de constituir modos de intervenção capazes de propiciar aos jovens a construção de novas ferramentas para fazer frente às precariedades dessas redes. Possibilitou, também, constatar a necessidade de capacitação dos agentes de saúde mental em práticas que acarretem menos reinternações, situação essa de característica reincidente e quase naturalizada pelas redes de saúde mental em que o serviço se apóia.

O trabalho de Diehl (2007) abordou os efeitos da utilização de uma câmara fotográfica digital pelos usuários e técnicos do serviço. Analisou tanto o uso da máquina, a produção de imagens assim como os efeitos de uma exposição de fotografias no contexto do hospital. Em seu estudo o autor constatou que esse modo de intervenção produziu uma torção no regime de visibilidades existente no serviço. Os jovens, que são colocados muitas vezes em um lugar de objeto do olhar técnico especializado, pelos diagnósticos e práticas terapêuticas, ocuparam uma posição diferenciada ao segurar a câmera fotográfica. Isto se deu em função da capacidade deste aparato de fixar imagens que são discursivamente tomadas de um alto grau de legitimidade, dado que, como herança da modernidade, considera-se a imagem fotográfica, muitas vezes, como uma re- 
presentação do "real" visível (DUBOIS, 1994). Além desta "torção" nas posições enunciativas, as oficinas de fotografia permitiram que os jovens atualizassem o seu olhar sobre a instituição. Pois consideramos que, apesar do senso comum separar, muitas vezes, a fotografia e o sujeito que a produziu, tais imagens são resultado de escolhas e da forma de olhar deste sujeito. Os jovens, através da fotografia, tornaram visíveis outros aspectos presentes, porém invisibilizados, do cotidiano do contexto: detalhes prediais, aspectos da flora e da fauna, imagens possíveis e proibidas, que no cotidiano do operar da instituição passam despercebidos (DIEHL; MAURENTE; MARASCHIN, 2007).

O resultado dos trabalhos anteriores permite inferir que as produções das crianças e dos adolescentes, dos oficineiros e dos pesquisadores constituem um espaço de encontro-comum.

O objetivo deste artigo é discutir a experiência de oficinas tecnológicas baseadas na construção compartilhada de um blog pelos jovens em atendimento no CIAPS. Para isto, buscaremos destacar as peculiaridades desta ferramenta no processo em questão, desenvolvendo uma linha de pensamento que aponte para as possibilidades de exercício de uma autoria por parte dos jovens.

\section{As Tecnologias como potência criadora no contexto da Saúde Mental}

Pensar na questão da autoria é falar, principalmente, na condição de compartilhamento da fala e das produções de um sujeito. Nesse estudo, a questão central da autoria se vê confrontada com um impasse significativo:. Como estabelecer as condições para que crianças e adolescentes usuários de um serviço de saúde mental, e, por conseguinte, discursivamente situados numa estreita relação à loucura, possam fazer o exercício de narrar suas histórias de forma que encontrem o compartilhamento necessário à assunção de uma posição de autoria? Como estabelecer as condições necessárias para que o compartiIhamento das produções construídas tenha como efeito a emergência de sujeitos legitimados em seu saber, de uma experiência, em um local historicamente marcado por um saber que destitui o "louco" de sua condição de sujeito? Constata-se que para esses sujeitos as redes de conversação de que participaram ou ainda participam (embora na maioria dos casos esses jovens estejam desvinculados de instituições como a família e a escola) não lhes retornam um reconhecimento de suas ações, deslegitimando, na maioria dos casos, suas produções.

Em contraponto a uma perspectiva que situa a autoria como decorrente de uma competência cognitiva individual, pensamos esse conceito como um modo de viver no linguajar, no conversar. Para Maturana et al (1999), aquilo que chamamos de idéias não se produzem na interioridade corporal - ainda que dependam dela e existam através dela - mas sim na dinâmica relacional. As idéias e, do mesmo modo, as competências são forjadas em redes de conversações onde as palavras e as ações seriam nós de coordenações que ganham consensualidade e sentidos nas condutas e emoções que coordenam. Nessas redes as tecnologias participam ativamente nas reconfigurações dos sentidos e significados, levando-nos a concluir que o conversar se produz de modos diversos em diferentes domínios relacionais; ou seja, geramos tais idéias e competências ao vivermos em distintos domínios de relação e com diferentes tecnologias.

Assim sendo, a autoria é aqui entendida como um modo de produção do mundo e de si mesmo, e não como uma competência cognitiva que se possua como um atributo próprio de característica atemporal e descontextualizada. Trata-se de um processo que não encontra ponto de estabilização, mas que se relança a cada passo (RICKES, 2002). Apesar de a autoria implicar uma posição de atividade, um protagonismo frente aos desafios que o outro e o mundo colocam, ela requer que nas redes de conversação o sujeito se deixe capturar pelas suas tramas que imprimem marcas específicas e abrem condições singulares para quem delas participa. É somente se deixando capturar que cada um poderá experienciar uma posição subjetiva proativa e diferenciada dentro de uma rede de conversação.

Assim, a idéia de autoria aqui trabalhada implica a possibilidade de produzir uma diferença, um "ruído", em uma rede de conversação e ser, ao mesmo tempo, marcado nessa rede pela diferença produzida. Diferentemente da idéia de "ruído" como algo que deve ser 
minimizado para dar lugar a uma comunicação "limpa", em nossa perspectiva, o ruído é o próprio motor da dinâmica conversacional. Ele não é algo externo ao processo de linguajar, mas é o motivo pelo qual a dinâmica relacional se produz. Dessa forma, ao conversarmos para produzir coordenações de coordenações consensuais de ação que configuram mundos de sentido compartilháveis, as redes de conversação dão suporte para o exercício da escrita, envolvendo tanto uma produção singular, como, um reconhecimento pela rede da diferença produzida e compartilhada no blog. É por essa razão que podemos indicar que a autoria implica a produção de uma diferença em uma rede de conversação. Efeito de uma posição de sujeito capaz de estranhar, questionar, refletir sobre o conversar e nele encontrar diferença, descontinuidade, ruptura, posição distinta de um eficiente tradutor ou aplicador de idéias que buscam a identidade, a semelhança.

Assim, propomos que a posição de autoria emerge quando uma operação fecha um determinado circuito em anel:

a) um sujeito produz uma diferença pelo (e no) atravessamento da rede de sentidos em que vive.

b) essa produção é compartilhada nesta (por esta) mesma rede de sentidos.

Tomada essa perspectiva é necessário reforçar a idéia - que poderia parecer inicialmente paradoxal - de que a função autor é uma auto-produção-dependente: se constitui e se atualiza por um sujeito modulado pela interseção dos agenciamentos sociais - que chamamos de instituições - e das tecnologias que configuram as redes de conversação. Caberia então pensar que a possibilidade de produzir efeitos de diferença em uma rede posição de autoria - também é condicionada pela ecologia cognitiva na qual essa rede de conversação se produz (LEVY, 1998). A autoria é redesenhada, ressignificada, implicando outras formas de atualização dependendo da ecologia cognitiva na qual é exercida. Guiados por essas relações entre autoria, rede de conversações e de possibilidade de compartiIhamento que vimos estudando em um contexto de comunicação específica o desdobrar de escritas produzidas por crianças e jovens usuários de um serviço de saúde mental, ao disporem de ferramentas tecnológicas de comunicação, interação e produção.

A elaboração que aqui apresentamos objetiva investigar e analisar alguns desses modos de linguajar em um domínio de relação com especificidade própria. Trata-se de uma rede de conversação que se estabelece entre oficineiros, crianças e adolescentes usuários de um serviço de saúde mental, utilizando-se de ferramentas das tecnologias digitais, que incluem computadores conectados entre si e na Internet, máquinas fotográficas digitais e kits de robótica. Essa multiplicidade na configuração tecnológica dos espaços de circulação proposta às crianças e aos jovens lança mão de uma abertura a diálogos e escutas antes silenciados, estabelecendo uma rede de conversação que apostamos poder propiciar oo exercício de uma posição de sujeito, fato já mencionado como essencial para criar as condições de suporte ao exercício da posição de autoria.

O trabalho das oficinas tecnológicas oportuniza um rico campo de análise das possibilidades de constituição de um espaço de exercício de autoria, a partir da criação de um convite à inserção em um ambiente tecnológico que permite o compartilhamento de escritas, tão distintas daquelas que comumente se oferecem nesses serviços. Nesse artigo temos como propósito apresentar uma análise de algumas dessas produções. Cabe agora centrarmos, primeiramente, no método que delineamos para realizar o presente estudo.

\section{O blog como campo empírico}

O percurso da pesquisa dentro do serviço de saúde mental trouxe a necessidade de que os registros e produções deixadas pelos jovens pudessem ser visibilizadas e acessadas em espaço coletivo e público. A construção de um blog, http://www.oficinandoemrede. blogspot.com, vem ao encontro da idéia de um espaço de compartilhamento de escritas,

\footnotetext{
${ }^{1}$ Maturana (2001) define o linguajar como coordenações consensuais de coordenações de ações. A recorrência é necessária pois é nela que se instaura uma posição de observador. Vivemos coordenando ações com os outros que geram consensos pela recorrência das coordenações, mas é somente quando coordenamos as ações já coordenadas que emerge o linguajar e, com ela, a posição de observador.
} 
imagens e conversação, potencializador tanto para trocas internas entre os participantes, quanto às pessoas externas à instituição.

A ferramenta do blog, que tem em sua gênese o ideário de textos críticos individuais, é ainda hoje tomada na rede principalmente como espaço personalizado de escrita; no contexto do projeto, há a subversão, de certa forma, desse caráter restritamente pessoal, ao ser oferecido enquanto espaço de encontros múltiplos. De antemão, nossa trajetória no projeto nos permite tomar esse campo empírico como sendo constituído e compartilhado entre oficineiros e pesquisadores, e, por isso, potencial iminente a uma rede de conversação contínua e implicada. Jovens, autores das produções; oficineiros, mediadores na proposição das atividades; pesquisadores, analisantes do processo, são agentes atualizadores ás leituras possíveis das publicações, bem como a novas intervenções ao longo do projeto. Enquanto proposição de pesquisa, ao se organizar sob formato de oficina, o espaço constitui-se sob uma híbrida e múltipla negociação das atividades a serem desenvolvidas, tanto pelos diferentes grupos de jovens que a compõe, como pelas circunstâncias institucionais e delimitações da técnica de intervenção. Nessas oficinas, ao nomearmos como sendo aquele um espaço de "laboratório de informática", parece-nos dizer justamente do método laboratorial de proposições ás atividades. Explora-se a máquina em seus recursos e a rede externa em suas possibilidades de navegação, procurando-se eleger sempre disparadores temáticos, que ao fim do encontro, possam ganhar sentido para o grupo de participantes, a partir da publicação no blog.

Desde o seu início, em maio de 2007, os jovens participantes da oficina têm a opção de postar nesse espaço coletivo suas produções ou circular por seus posts, lendo-os e/ ou respondendo-os. Muitos buscam imagens na internet para publicar, outros escrevem, outros mandam mensagens para familiares e amigos, e outros apenas comentam os posts. Não há nenhuma regra estilística quanto ao que, nem como fazer as publicações, deixando os jovens livres para se expressarem. As publicações podem ser individuais, em duplas ou trios, ou ainda fazer parte de uma confecção inteiramente grupal, mas que embora seja de acesso e postagem compartilhada não permite, como na ferramenta "wikipédia", ser com- pletamente excluído ou alterado pelos demais participantes depois de postado. As trocas, os díalogos acerca de determinada postagem segue sempre sob a forma de comentários, podendo receber ou não a assinatura do mesmo que a postou. A ambivalente relação entre a evidência da assinatura individual nas postagens e a posição de autoria que aqui pretende-se analisar, diz-nos justamente da necessidade desses indivíduos primeiramente se reconhecerem enquanto sujeitos, para a partir daí também poderem ser reconhecidos enquanto diferença em um coletivo.

Tomamos nesse artigo o blog como campo empírico para pensar as formas de tramitação do conversar capazes ou não de fazer emergir exercícios de autoria. Como salientamos acima, as próprias postagens decorrem de um processo que se realiza no coletivo das oficinas. Podemos assim dizer que resultam já de uma rede de conversas que se produzem na própria atividade. A peculiaridade do blog, que comporta uma interação via comentários à cada postagem, pode dar base a uma conversa, que se desenrola nos sucessivos comentários. Conversas com relativamente poucos turnos e em tempos variados, uma vez que todas as postagens ficam acessíveis aos potenciais comentaristas. Conceituamos a conversa no sentido dado por Maturana ao conversar, ou seja, em um fluir no linguajar e no emocionar. Uma conversa que se estabelece e se sustentada por um emocionar que configure o outro como interlocutor em um coletivo de sentidos supostamente compartilhados ou não.

Além disso, acreditamos ter o blog também uma especificidade quando tomado como campo empírico. Ele se configura como uma espécie de repositório, onde os leitores dos trabalhos e das análises têm acesso ao conjunto desse campo. Essa acessibilidade não é comum nos trabalhos científicos, onde os leitores ficam restritos a maior ou menor inclusão pelo autor dos dados-fonte nos textos.

Tomaremos como analisadores para potencializar nossa indagação acerca das possibilidades de configuração de um exercício de autoria no espaço do blog as categorias que se seguem. Primeiro o blog como um espaço público de escrita, possibilitando relações de comunicação nas quais não se pode delimitar de antemão o receptor. Além de um possível endereçamento específico, as mensagens são também enviadas para a "rede", tendo como 
ponto de mira um horizonte impessoal não muito delimitado. Esse tipo de comunicação se distingue das outras modalidades geralmente utilizadas pelos usuários e pela própria instituição. Elegemos como segundo analisador a peculiaridade da escrita no blog. Essa peculiaridade ultrapassa os limites formais da língua, aos quais os jovens em atendimento estão muitas vezes afastados por sua própria história de escolarização. Nesse espaço, os "erros" relacionados a uma escrita formal podem estar menos visibilizados se legitimados por estilo "blogueiro" de escrever. Essa relativa "camuflagem" dos erros formais na escrita possibilita que os jovens não se intimidem tanto em postar suas idéias e mensagens. 0 que pode ser um facilitador à emergência de uma posição de autoria. O terceiro ponto de análise destaca o blog como um espaço híbrido de escritas e imagens o que possibilita uma ampliação das modalidades de registro e de comunicação.

\section{Blog Oficinando, novas formas de compartilhamento às escritas}

Se, por um lado, a escrita em blogs tem-se popularizado, tornando-se um grande interesse para jovens de quase todas as idades, no $\mathrm{CI}$ APS ela terá algumas peculiaridades. A primeira delas é que os jovens ali internados estão afastados de suas redes sociais e afetivas e a possibilidade de criação de novas redes de convivência pode ser fundamental quando se entende a atenção ao sofrimento psíquico de um modo mais amplo. A troca de experiências, gostos musicais, busca de amizades e a descrição da cidade de onde se vem² são constantes postagens do blog.

oi sou a marialívia ${ }^{3}$ eu quero conheser alguns amigos e amigas e ser amiga de varias pesoas legais vamos mudar de asunto eu tenho 11 anos tenho 1metro e40 sou branca cabelos preto sou magra vamos mudar de asunto gosto de jogar bola sou de santa maria mas estou morando com omeu pai em canoas gosto de ir em baladas sair a noite sou legal com osmeus amigos

O blog é como um "espaço" de acesso público e particularmente legitimado, o que permite que as produções dos jovens ganhem um olhar diverso do olhar unidirecional carregado de sentidos a priori estabelecidos que normalmente recebem em instituições como os hospitais psiquiátricos. Isto abre a possibilidade de um outro endereçamento para as produções, o que permite que os jovens se coloquem de outras formas na relação e não apenas como loucos, doentes ou usuários de drogas. No post acima citado a menina procura amigos como habitualmente fazem os adolescentes que utilizam a Internet e apresenta-se por seus interesses, gostos e aparência física.

O blog, como um espaço publicamente acessível, permite uma visibilidade diferenciada daquela que as produções dos jovens na instituição normalmente encontram. $\mathrm{Na}$ instituição psiquiátrica - e também fora dela, considerando-se um regime de verdades que coloca o louco, o usuário de drogas, o "doente" mental, em uma posição objetalizada diante do saber médico especializado - o que se percebe, no mais das vezes, é uma deslegitimação e um apagamento de tais produções. Sendo assim, poderíamos pensar que, neste contexto específico, o fato de poder ter como interlocutor um "fora" potencialmente interessado, poderia ensejar a produção de uma diferença em uma rede de sentidos. O exercício desta diferença pelos jovens em uma instituição psiquiátrica poderia ser considerado um exercício de autoria.

Mas isto não depende somente da configuração da oficina, do recurso tecnológico em questão e do interesse dos jovens. A produção de uma diferença em uma rede de sentidos não está articulada unicamente à instituição psiquiátrica, dado que se procura também uma nova relação com um "fora". Isto nos leva a pensar em uma terceira peculiaridade dos blogs no projeto com oficinas em saúde mental, que é o interessante encontro entre o que se poderia chamar de uma cultura de blog e os jovens em tratamento no CI APS. Tal cultura diz respeito às publicações em geral na Internet que, por serem realizadas por uma diversidade muito grande de pessoas, passam a abrigar incontáveis estilos, formas de escrever, níveis de adesão à língua formal, veracidade de informações etc. O caráter público e a diversidade presente na Internet garantem, de

\footnotetext{
${ }^{2}$ Os jovens que internam neste serviço não são residentes da cidade de Porto Alegre, de modo que cada um costuma vir de uma região diferente do estado.

${ }^{3}$ Os nomes são fictícios.
} 
certa forma, a legitimação da singularidade.

No post supracitado, por exemplo, existem alguns desvios da língua escrita formal, tanto ortográficos quanto gramaticais. Se isto acontece na escola, no hospital ou em outros diversos locais, encontramo-nos diante de uma tendência à significa-lo como um erro. $\mathrm{Na}$ Internet, contudo, o que se observa é que os "erros" podem ser considerados um estilo do autor. A decorrência disto é a invenção de novas formas de escrita que, muitas vezes, aproximam-se da escrita formal e, outras, misturam letras maiúsculas e minúsculas, imagens e palavras. A escrita no blog tolera ser experimental sem, com isso, por em risco a sua legitimidade. Consideramos, com isso, que esta cultura blogueira pode ser uma estratégia quando se busca dissolver o regime normalizador da instituição psiquiátrica, dando ênfase à singularidade dos jovens. Por esta razão, os "erros" nunca são corrigidos pelos oficineiros e os resultados são interessantes mesclas entre estilos de escrita de blog e desvios da língua formal, como se pode ver no exemplo abaixo:

Rui publica:

Sou o Rui, tenho 14 anos e gostaria de conhecer vocês por foto. Até quarta! Para as gurias que gostaram da foto do Snoop Dog. Um beijo do Rui!

Mariane comenta:

oiiieee gostei de sua foto se der vamos nos conhecer pelo blog sab eu to aprocura de amigos vo publica qualquer coisa que eu acha de bm pra se der nos se conhessermos se vc kiser ta ???!! bjkass

Neste diálogo Mariane utiliza uma linguagem comum em chats e blogs em que algumas letras são trocadas para aproximar a escrita da fala e para agilizar o processo de digitação. Isto começou em chats para dar velocidade à conversação e seguiu como um estilo em diversas publicações na rede. Para navegadores familiarizados com esta escrita fica claro quando se trata disso ou quando se trata de um afastamento do português correto. Para pessoas menos habituadas isto pode confundir, como no caso da palavra "kiser". O que nos interessa ressaltar é o fato de que os jovens podem transgredir a língua formal, inventando novos estilos, produzindo diferen- ças. Essa transgressão, tanto no que concerne á escrita na rede quando ao que concerne ao fazer dos jovens, embora tida por parâmetros exteriores como uma infração, revela uma filiação. A escrita fonetizada é sinal de domínio e familiaridade com o ambiente virtual e, nesta medida, confere legitimidade e um certo status ao seu autor. Assim, as dissonâncias operadas pelos textos dos jovens no blog, uma vez inscritas neste território, são capazes de se apresentar como diferença sem perder o elo com os ordenadores do coletivo que regula as relações neste espaço. Esses são alguns modos de exercício de autoria utilizando como estratégia oficinas tecnológicas.

Outro aspecto a ressaltar na produção das postagens do blog, além da modalidade de escrita, consiste no amplo acesso ao conteúdo imagético e discursivo possibilitado pela Internet. A facilidade pela qual se dispõe de uma diversidade de imagens, através de buscadores como o Google, permite uma ampliação do repertório para muito além do que alguém poderia colecionar através de meios convencionais. A escolha, colagem e composição de imagens possibilitam aos jovens um incremento da expressividade, principalmente, pela explicitação de emoções, que podem vir a se constituir em links de coordenações e de produção de pequenas redes de conversa. Algumas postagens fazem propostas de temáticas específicas, tais como, grupos musicais, objetos de desejo e de consumo, personagens da mídia... Outras convidam ao compartilhamento, modulando ora a força da textualidade e ora a força das imagens.

O jogo recorrente entre o acesso a um arquivo mundial de imagens e as escolhas e composições singulares permitem um deslocamento entre o coletivo e o singular capaz de abrir espaço ao exercício da autoria. Uma temática recorrente no blog é a referência às cidades e aos locais de proveniência acompanhada pela necessidade de sustentar uma modalidade de cidadania, singularizando um pertencimento a um coletivo - o que denota um dos movimentos presentes no jogo da autoria, tal como conceituamos acima.

Essas postagens trazem referências de pertença a uma rede que coloca os jovens como moradores de uma determinada cidade. Geralmente são postagens que estimulam trocas, comentários. Tal como os decorrentes da primeira postagem intitulada "minha vila": 


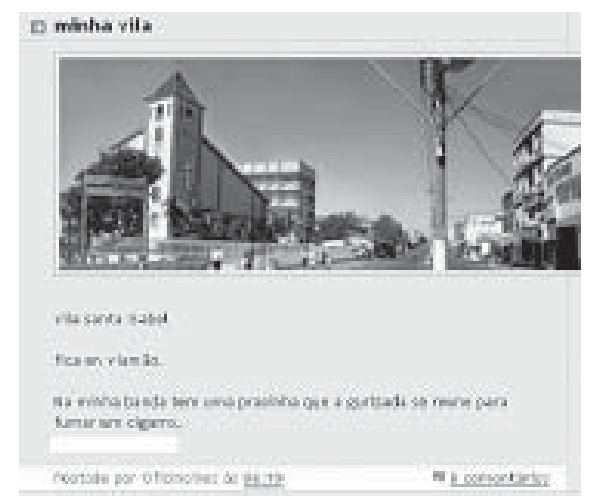

Figura 1 - Minha vila

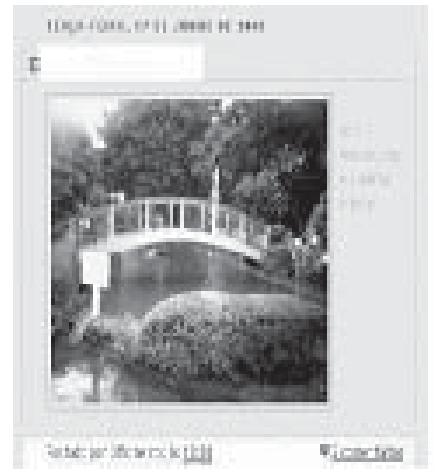

Figura 2 - Minha cidade

$1^{\circ}$ Comentário:

Eu fumo baseado la... (12 de Setembro de 2007 06:41)

\section{Comentário:}

Pessoal além de fumar, o que mais lhes interessa na praça? Que coisas interessantes se tem para fazer na cidade? Que lugares legais de conhecer? Que pessoas vocês gostam de encontrar? Tatiane (16 de Setembro de 2007 12:17)

\section{$3^{\circ}$ Comentário:}

EU JÁ ESTIVE AI MAS POR QUE VC TEM ISSO NO NOME GORDO APOSSTO QUE VC É DESSENTE NÃO PRESSISA SER GORDO OU MAGRO OQ EMPORTA É SUA MANEIRA DE SEESPRESSAR JBJBJBBJBJBJBJ MARIANE (17 de Setembro de 2007 10:29)

$4^{\circ}$ Comentário:

PRETENDO TE CONHECER MELHOR AQUI NO CHAT (17 de Setembro de 2007 10: 30)

\section{$5^{\circ}$ Comentário:}

quero te conhecer melhor também porque o meu apelido é gordo? porque a gurizada botou... (19 de Setembro de 2007 06:03)

\section{$6^{\circ}$ Comentário:}

sou Márcio Mariana (19 de Setembro de 2007 06:06)

A conversa gerada a partir da postagem de Márcio no dia 12 de setembro se desenrolou até 19 de setembro. Apesar de sua brevidade, nessa conversa assistimos ao estabelecimento de uma troca através da qual alguns nós de identificação foram se deslocando, possibilitando dar visibilidade a uma rede de pertencimento: cidade-apelido-nomes. Podemos dizer que essa pequena conversa possibilitou a constituição de um emocionar de aceitação, através do qual esses deslocamentos do coletivo ao singular foram possibilitados.

Um conversar, como conceituado acima, que se produz no fluir do linguajar - que remete à tensão do coletivo-singular - e do emocionar que abre um campo de compartiIhamento possível. Tal como na conversa anterior, a aceitação da legitimidade do outro fez com que os deslocamentos se produzissem até que se produzisse a confiança necessária para assinar com o próprio nome a mensagem, identificando-se. Aqui, a identificação opera em duas direções: se fazer ver pelo outro e por obra disso desenhar as bordas de um lugar para o eu - sou fulano de tal.

Existem postagens nas quais a textualidade se coloca como principal elemento de vinculação da conversa. São vários os convites para continuar histórias ou para compartilhar alguma adivinhação. Na postagem abaixo a participante convida para que continuem uma história que iniciou.

A partir do convite uma pequena história começou a ser produzida:

$1^{\circ}$ Comentário:

Este homem foi fazer um curso para ser astronauta e teve uma grande surpresa, ganhou uma passagem para ir à Lua!!

Então ele... (7 de Novembro de 2007 09: 08)

\section{Comentário:}

viajou no espaço para conhecer as estrelas do espaço mundial e as gálacias e meteoros em volta do planeta com o sistema olar....?

quem disse é maria barros souza. (12 de Novembro de 2007 08:51) 


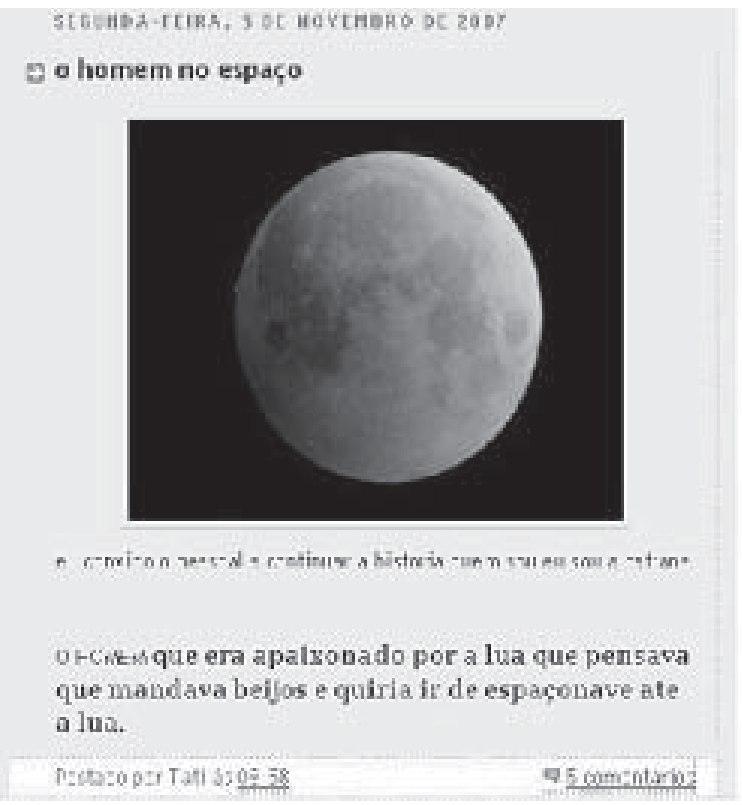

Figura 3 - O homem no espaço

\section{$3^{\circ}$ Comentário:}

quando viu um planeta muito grande de cor vermelha... Quando ele parou a nave encontrou... Continuem

Abraços Maria (19 de Novembro de 2007 08:51)

\section{$4^{\circ}$ Comentário:}

Ele encontrou algumas coisas neste planeta. Ficou espantado... (21 de Novembro de 2007 17:19)

\section{$5^{\circ}$ Comentário:}

q bm esse taxto bjkass amiguxa (10 de Dezembro de 2007 08:30)

Apesar de se constituir em um "início" de história, a possibilidade de compartilhar um contexto significativo criado pela conversa possibilita exercícios de coordenação de ações, uma vez que cada contribuição deve estar em relação com as anteriores, produzindo um conjunto que, ao mesmo tempo convida e modula uma participação. Novamente se visualiza o jogo do coletivo (organização textual) e o singular (contribuição de cada um). A dimensão singular pode se sujeitar ou não a um certo constrangimento coletivo, como a participação da última intervenção que faz um comentário avaliativo sobre a troca até então realizada.

Um exemplo dessa intertextualidade e participação pode ser observado na história “O menino e o gato" que foi construída a partir de um chat entre os participantes da oficina e após publicada no blog. Nesse caso, as participações foram constituindo uma estrutura textual que modula cada participação. Aceitar participar dessa rede implica também ter potencializado o exercício de autoria. Ou seja, cada nova frase era uma pequena diferença que fazia uma composição com a estrutura que estava sendo montada. Na versão para o blog não está revelada a autoria de cada contribuição. Ao final do texto os participantes assumem a sua integralidade.

O menino e o Gato (setembro 2007)

era uma vez, um gato brincalhao. ele tinha um dono chamado gabriel. gabriel era um menino muito exibido.

O nome dele é Epaminondas. Epminondas era branco e tinha o pelo muito fofo ELE ADORAVA LEITE Ele gostava de comer peixe e correr atras das borboletas. ELE ERA TIMIDO em um certo dia, epamiondas, o gato, tombou com um outro gato, chamado house, que significa * casa*. ele tinha esse nome porque ficava o tempo todo dentro de casa. house so saia de casa para incomodar os outros gatos. House era chato e bobalhão e só gostava de fazer maldade para os outros. ELE VIROU AMIGO DEHOUSE gabriel foi para a escola e deixou seu gato em casa, na escola, gabriel inventou de fazer uma historinha sobre seu, baseada no futuro do dois, ou seja, sobre ele e seu gato GABRIEL PENSOU EM DEIXAR OS DOIS FAMOSOS fez. quando terminou a aula, ele foi direto para casa. quando chegou, viu a casa toda revirada. foi logo chamando epamiondas. gritou tao alto que sua mae ouviu-lhe e disse: por que voce esta gritando, filho? gabriel respondeu: olha so, mae, o que epamiondas fez. e voce nao viu nada? a mae respondeu: mas como eu iria ver, se eu estava dormindo? gabriel, muito esperto, respondeu: e voce nao ouviu o barulho? quer saber!nao.foi uma bagunca!!!Epaminondas deixou rstos de comida espalhados! Soltou pelo nos móveis ELE RESPONDEU não Gabriel ficou muito brabo com Epaminondas porque ele teve que limpar tudo!mas, depois de muito tempo, eles resolveram.quando foram para o quintal, viram epamiondas e house estragando a grama.maria, mae de gabriel, ficou louca, e disse: o que eu faco para eles pararem, filho? gabriel pensou e disse: deixa comigo, mae. quando eu ler a historinha que fiz sobre epamiondas, ele vai parar de baguncar. gabriel chamou epamiondas e disse-Ihe: sente-se quieto que eu vou ler uma historinha sobre voce. epamiondas sentouse e ouviu seu dono falar. depois de ouvi tudo aquilo,,epamiondas nunca mais fez bagunca em casa ou qualquer outro lugar. sobre o que falava a historia, eu nao sei. e um misterio. ELE SEMPRE TAVA COM HOUSE BEM FELIZ

Téo

Mar

Adriane 
A história de Gabriel e Epaminondas, pelo modo como foi construída resultou de uma autoria coletiva onde o exercício da singularidade se produziu em um marco compartiIhado. Podemos retomar aqui que o exercício da autoria sempre depende de uma proposição singular que é acolhida pelo coletivo. Essa acolhimento se dá de diversas formas como no caso, na constituição de uma história. Ter sua contribuição inscrita na história é signo desse acolhimento.

\section{Considerações finais}

A discussão sobre o tema da autoria em um contexto institucional de um serviço de saúde mental no qual os sujeitos, crianças e jovens, apesar de sua pouca idade estão confrontados com experiências da loucura, do empobrecimento de vínculos sociais e culturais é desafiadora. Ainda mais quando essa discussão toma como objeto uma intervenção que se dá a partir de produções com tecnologias, não ficando restrita a uma análise teórica, mas instituindo uma intervenção.

A peculiaridade de uma oficina que utiliza recursos das tecnologias digitais em um serviço de saúde mental tem sido objeto de investigação conjunta da Universidade e dos trabalhadores do serviço. Ao compartilharmos com a instituição de saúde a modalidade oficina, que é uma prática corrente na maioria dos atendimentos prestados (com exceção dos atendimentos individuais...), compartilhamos um espaço de criação, no qual estão postos à disposição dos participantes ferramentas e objetos técnicos que potencializam diferentes construções. No caso, objetos técnicos que manipulam símbolos. Não queremos com isso dizer que as produções que emergem nessa oficina, da qual algumas foram mapeadas nesse artigo, não possam acontecer em outras oficinas que se organizem com outras ferramentas de criação. Mas cremos que diferentemente de uma ferramenta que amplia as potencialidades e funções do corpo, as tecnologias digitais mudam nossa relação com os artefatos técnicos e, com isso, com outros humanos.

Se aceitamos a noção de objeto técnico de Simondon (1989) como aquele que fixa e cristaliza o gesto humano em estruturas que funcionam estamos diante de um objeto que tem em seu operar uma correspondência operativa com as operações que fazemos entre nós. Essa peculiaridade é aquilo que, para o autor, aproxima-nos ou nos assusta frente aos objetos técnicos. Assim, à diferença das ferramentas, os objetos técnicos equipam os sujeitos com operações que não são possíveis de serem atualizadas com as ferramentas. Um computador, ligado a Internet, equipa os sujeitos de nossa pesquisa a partilhar, a conversar com um outro indeterminado. A rede mundial de computadores consiste em um coletivo impessoal e imprevisível. Lança-se postagens para a rede. É certo que os comentários que retornaram às postagens eram na sua grande preponderância de pessoas vinculadas ao serviço ou ao projeto. Mas também houve mensagens que foram postadas por viajantes que de alguma forma encontraram a página do blog. Embora o possível não seja totalmente realizado, a virtualidade dessa possibilidade (que as postagens possam ser recebidas por qualquer um que circula na rede) traz uma dimensão que não está posta em qualquer objeto técnico.

Além desse "fora" que acata as publicações e é virtualmente capaz de se constituir em um leitor, a rede mantém um acervo múltiplo de imagens, sons, textos que podem ser acessados dependendo da versatilidade dos sujeitos. A possibilidade de acesso a esse repositório mundial coloca os sujeitos de nosso estudo diante de uma riqueza simbólica que certamente é quantitativamente maior do que já experimentaram. Apesar da quantidade não ser suficiente para uma re-apropriação criativa ela sem dúvida abre um campo de possíveis. As apropriações que as crianças e adolescentes fazem revela as vicissitudes de seu histórico escolar, tal como registrado em seus modos de escrever. Mas revelam também a busca por estar em rede, constituir amizade e trocas.

Se as conversas não apresentam uma longevidade ou uma densidade maior, elas revelam intensamente esse movimento entre o coletivo e o singular capaz de sustentar o exercício de autoria. O fato do blog atualizar todas as postagens cria um link no tempo, algo que pode se manter no movimento e não somente na fixidez dos outros suportes, tal como um livro, uma folha de papel ou escritos sob uma parede do serviço.

Os recortes aqui selecionados não esgotam a possibilidade das análises dessas postagens. A ampliação da duração da experiência pode tornar visível os seus efeitos para além da du- 
ração da permanência desses jovens no serviço. Se a autoria se constitui a cada ato de passagem do coletivo ao singular em um circuito em anel que se diferencia a cada movimento recursivo, seus efeitos podem continuar reverberando em outras experiências.

\section{Referências}

DEMOLY, K. R. A.; MARASCHIN, C. Tecnologia, escritura e diferenças perceptivas: a criação hipertextual de professores. In: ENCONTRO NACIONAL SOBRE HIPERTEXTO, 2., 2007, Fortaleza. Anais... Fortaleza: [s.n.], $2007 a$.

DEMOLY, K.; MARASCHIN, C. Technologie, écriture et differénce. In: COLLOQUE INTERNATIONAL DU CHAPITRE FRANÇAIS DE LISKO, 6., 2007, Toulouse. Annales... Toulouse: Universite Paul Sabatier Toulouse III, 2007b. v. 1. p. 11

DIEHL, R. Do mapa à fotografia: planografias de um espaço louco. 2007. 87 f. Dissertação (Mestrado em Psicologia do Desenvolvimento) - Instituto de Psicologia, Universidade Federal do Rio Grande do Sul, Porto Alegre, 2007. Disponível em: <http://www. bibliotecadigital.ufrgs. br/da. php?nrb=000587643\&loc=2007\&l=ed 96114lab7a9e14>. Acesso em: 2007.

DIEHL, R.; MAURENTE, V. S.; MARASCHIN, C. Percursos fotográficos em um serviço de saúde mental. In: ENCONTRO NACIONAL DA ABRAPSO, 14., 2007, Rio de Janeiro. Anais... Rio de Janeiro: ABRAPSO, 2007.

DUBOIS, P. O ato fotográfico. Campinas: Papirus, 1994.

FRANCISCO, D. Intervenção em Saúde Mental: formação de redes de convivência via recursos informatizados. 59 f. Proposta de Tese (Doutorado em Informática da Educação)- Universidade Federal do Rio Grande do Sul, Porto Alegre, 2004.

FRANCISCO, D. J.; AXT, M.; MARASCHIN, C. Informática e saúde mental: caminhos de uma oficina. RENOTE. Revista Novas Tecnologias na Educação, Porto Alegre, v. 5, n. 2, p. 1-16, 2007.

LEITE, M.; FILÉ, V. (Orgs.). Subjetividade, tecnologias e escolas. Rio de Janeiro: DP\&A, 2002.

LÉVY, P. A ideografia dinâmica: rumo a uma imaginação artificial?. São Paulo: Loyola, 1998.

MATURANA, R. H.; MAGRO, C., GRACIANO, M.; VAZ, N. M. A ontologia da realidade. Belo Horizonte: Ed. UFMG, 1999. (Humanitas, 14).

MATURANA, R. H.; MAGRO, C.; PAREDES, V. Cognição, ciência e vida cotidiana. Belo Horizonte: Ed. UFMG, 2001. (Humanitas, 58).

PAULON, S. [Humanização da atenção e gestão do SUS]. Projeto de curso de pós-graduação lato sensu em humanização da atenção e gestão do SUS. Porto Alegre: Universidade Federal do Rio Grande do Sul, 2006.

RAINONE, F. N. A plurissemia das imagens cinematográficas e a polissemia do significante na psicose: uma relação entre imagens e narrativa. 2007. 157 f. Dissertação (Mestrado em Psicologia Social e Institucional)Universidade Federal do Rio Grande do Sul, Porto Alegre, 2007.

REAL, L. C.; MARASCHIN, C.; AXT, M. Projetos de aprendizagem e tecnologias digitais: uma experiência promovendo transformações na convivência na escola. RENOTE. Revista Novas Tecnologias na Educação, Porto Alegre, v. 5, n. 1, p. 1-11, 2007. 
RICKES, S. M. No operar das fronteiras, a emergência da função autor. 2002. 195 f. Tese (Doutorado em Educação) - Universidade Federal do Rio Grande do Sul, Porto Alegre, 2002.

RODRIGUES, S. C.; MARASCHIN, C.; LAURINO, D. P. Rede de conversação, formação de professores e tecnologias digitais. Cadernos de Educação, Pelotas, v. 16, p. 65-70, 2007.

SCISLESKI, A. C. "Entre se quiser, saia se puder": o percurso dos jovens pelas redes sociais e a internação psiquiátrica. 2004. 184 f. Dissertação (Mestrado em Psicologia Social e Institucional)- Universidade Federal do Rio Grande do Sul, Porto Alegre, 2004. Disponível em: <http://www.bibliotecadigital.ufrgs.br/da.php?nrb $=000539817 \& \mid \mathrm{loc}=2006 \& \mathrm{I}=\mathrm{cfb} 747 \mathrm{cf} 7 \mathrm{db} 8 \mathrm{f} 3 \mathrm{a} 8>$. Acesso em: 2006 .

SCISLESKI, A. C. C.; MARASCHIN, C.; SILVA, R. N. Manicômio em circuito: os percursos dos jovens e a internação psiquiátrica. Cadernos de Saúde Pública, Rio de Janeiro, v. 24, p. 342-352, 2008.

SIMONDON, G. Du mode d'existence des objets techniques. Paris: Aaubier, 1989.

Recebido em maio de 2008

Aceito para publicação em junho de 2008

\section{Nithiane Capella}

UFRGS

nithiane@yahoo.com.br

\section{Cleci Maraschin}

PGIE e PPGPSI UFRGS

cleci.maraschin@ufrgs.br

\section{Vanessa Maurente}

PGIE UFRGS

vanessamaurente@yahoo.com.br

\section{Simone Moschen Rickes}

FACED UFRGS

simone.m.r@via-rs.net 